\title{
“AQUI NAO É RUÍNAS QUILMES, É A CIDADE SAGRADA QUILMES" - DISPUTAS PATRIMONIAIS EM TORNO DE UM SÍTIO ARQUEOLOGICO NO NOROESTE ARGENTINO
}

\section{A U T O R}

\section{Frederic Pouget}

pouget@yahoo.com
Bacharel em Ciências Sociais-USP, Mestre em Arqueologia-USP e Doutorando em História Cultural - UNICAMP. Bolsista de doutorado FAPESP
R E S U M O

A B S T R A C T
A história dos índios quilmes, situados no noroeste argentino, representa um caso paradigmático nos termos de um discurso patrimonial. Na Ciudad Sagrada Quilmes, não só encontramos os vestígios arqueológicos monumentais dessa antiga cultura andina, mas também discursividades que refletem aspectos de dominação e resistência vivenciada por esse povo. Toda essa trajetória pode ser seguida tomando como exemplo os aspectos patrimoniais do sítio arqueológico-Ciudad Sagrada Quilmes- sendo possível, portanto, refletir sobre o caráter de agentes históricos das populações nativas e como elas atuam frente a verdades históricas (acadêmicas ou não) exteriormente elaboradas. Tais questões se aproximam do debate teórico sobre etnicidade (BARTH, 1969; 1998; POUTIGNAT e STREIFF-FERNANT, 1998), que, no caso quilmes, se correlaciona diretamente com o sitio arqueológico e com sua perspectiva de memória coletiva histórica evidenciada pela disputa patrimonial.

Palavras-chave: Patrimônio, Discursividades, Quilmes.

The history of the Quilmes Indians, located in the northwestern Argentina, is a paradigmatic case in terms of heritage discourse. In the "Ciudad Sagrada Quilmes", we found not only the monumental archeological remains of this ancient Andean culture, but also discourses that reflect aspects of domination and resistance experienced by these people. This entire trajectory can be fallowed if we have in account the heritage aspects of the archaeological site - Ciudad Sagrada Quilmes- that implies to reflect the native population as agent of his history and how they act in face of historical truths (academic or not) externally developed. Such questions are closer to the theoretical debate about ethnicity (BARTH, 1969; 1998; POUTIGNAT; STREIFF-FERNANT, 1998), and correlates directly with the archaeological site and quilme's historical perspective of collective memory evidenced by heritage dispute.

Keywords: Heritage, Discourse, Quilmes. 


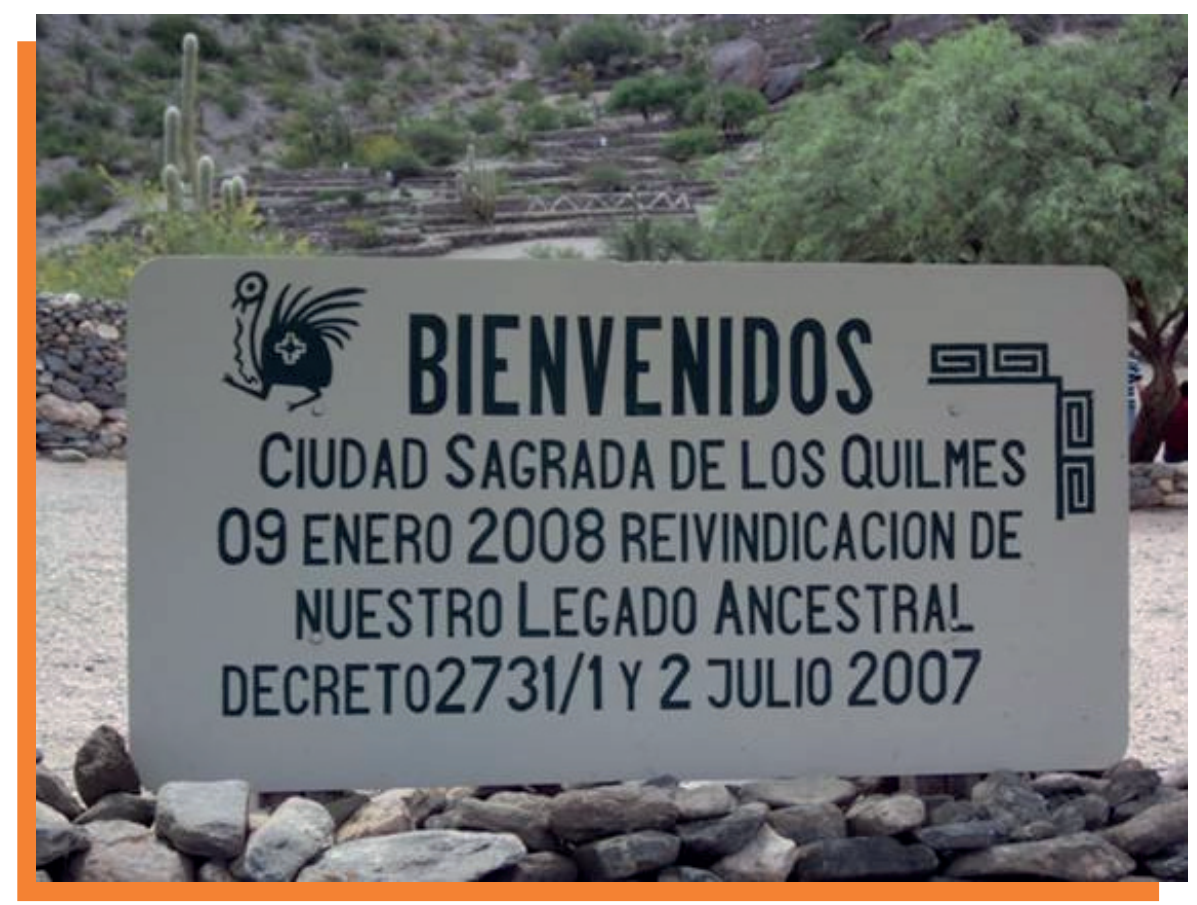

Figura 1: Placa de apresentação da comunidade para os visitantes junto ao sítio arqueológico.

I N T R O D U Ç Ã O
O intuito deste trabalho é fornecer uma reflexão em torno das problemáticas de disputa patrimonial e da disputa de sentidos históricos envolvidos neste mesmo patrimônio. Esse contraste é mais explícito no caso quilmes, por ser tratar de uma população indígena que traz para si uma compreensão própria de etnicidade em torno do sitio arqueológico e da memória histórica. (BIDASECA e RUGGERO, 2011)

O grupo indígena quilmes sofreu, durante o período colonial, um quase extermínio (ou total, se verificarmos o senso comum argentino que, até hoje, considera os índios como extintos), sendo as poucas famílias restantes obrigadas a se mudarem da sua cidade sagrada nos vales andinos para uma futura vila próxima a Capital Federal, à aproximadamente $20 \mathrm{~km}$ de distância (LORANDI e BOIXADOS, 1988; SARASOLA, 2010). Hoje, Quilmes é uma cidade que faz parte da Grande Buenos Aires e empresta o seu nome à cerveja mais popular da Argentina.

No entanto, os quilmes não desapareceram. Em um processo de tomada de consciência política por parte dos seus descendentes, eles tomaram para si - literalmente - sua herança histórica. As famosas "Ruínas de Quilmes", marco do turismo arqueológico argentino, passaram a ser controladas pela comunidade indígena em 2008, sendo ressignificadas como Ciudad Sagrada Quilmes, à revelia de arqueólogos, agentes governamentais e turísticos. Nesse sentido, a "Ciudad Sagrada Quilmes" não é somente um espaço de poder, mas é também um espaço de agência histórica para a resistência dos grupos oprimidos por um determinado processo de (des)territorialização (CARRASCO, 2000).

Cabe ainda a pergunta se a retomada da ação política por parte deste povo não estava presente bem antes desta intervenção, sendo a mesma só uma conseqüência do longo processo político identitário que os próprios quilmes, assim como outros povos indígenas argentinos, vêm manifestando nas últimas duas décadas. Isso se evidencia no período logo após abertura democrática no país, que aconteceu em 1983, depois de uma sangrenta ditadura que deixou, segundo os cálculos dos grupos de direitos humanos, mais de 30.000 mortos. 


\section{Historiografia do sítio arqueológico Quilmes}

A "Ciudad Sagrada Quilmes" localiza-se a oeste na província de Tucuman, em um território montanhoso (pré-andino), chamado de vale de Yokavil (ou Santa Maria), estendendo-se ao norte até os Vales Calchaquies. Esta paisagem geográfica é compartilhada pelas províncias argentinas de Salta, Tucuman e Catamarca. Nela, encontra-se também a famosa Ruta 40 (que refaz o antigo caminho incaico, o qual se estendia desde Cuzco até a atual província de Mendoza), que corta o país do Norte até o extremo meridional Patagônio.

O Pucará de Quilmes é um dos exemplos das cidades fortalezas do período pré-colonial da Argentina. Sua população se desenvolveu deste o século $X$, alcançando uma enorme complexidade cultural, com manejo agrícola e hidráulico, relações de intercâmbio político e econômico com o império incaico e sendo uma das principais frentes de resistência perante colonizador espanhol. Todavia, ao serem derrotados militarmente em 1667 (durante a terceira guerra calchaqui), sendo compelidos a um êxodo forçado, os 1000 indivíduos restantes (segundo cronistas, como D. Juan de Ceballos) foram instalados próximos a Buenos Aires (SOSA, 2007; LORANDI e BOIXADOS, 1988). No entanto, nem todos percorreram os $1500 \mathrm{~km}$ de êxodo. Várias famílias conseguiram fugir do cerco espanhol e se instalaram nas proximidades de sua antiga cidade.

Ao analisarmos um pouco mais a história cultural deste patrimônio arqueológico, podemos compreender o porquê da desconfiança em explicações interpretativas geradas por cientistas historiadores. $O$ período compreendido entre o final do século dezenove e o começo do século passado foi considerado como de florescimento da arqueologia argentina, consolidando a arqueologia enquanto ciência. (POLITIS, 1995; NASTRI, 2004; TARRAGÓ, 2003).

As primeiras indicações sobre os quilmes, nesta fase pioneira, são verificadas nos relatos de campo de Lafone Quevedo, em 1883, Ten Kate, em 1894, e, claro, na obra bibliográfica do eminente antropólogo/arqueólogo Juan Bautista Ambrosetti, La antigua ciudad de Quilmes (Valle Calchaque), de 1897, que implanta técnicas inovadoras de análises estratigráficas no noroeste argentino. Outros artigos pioneiros indicativos sobre os quilmes foram aqueles referentes a coletas de artefatos cerâmicos produzidos por LA VAUX (1901): "Execursión dans les Vallées Calchaquies (Provience de Tucuman). Poteries indigenes ». Atualmente, tais artefatos se encontram no Musée Quai du Branly, em Paris. ${ }^{1}$

Ainda no século XIX, Padre Lozano (1873) publicou Historia de la conquista cerâmica calchaquie também se encontra no Museu de Arqueologia da USP. Coleção esta adquirida de Juan Ambrosseti e Francisco Moreno por Hermann von Ihering, antigo diretor do Museu Paulista em 1904 (FERREIRA: 2010).

del Paraguay, Rio de la Plata y Tucuman, com algumas referências sobre os quilmes, especialmente sobre a suposta migração originária daqueles a partir do Chile. Por não citar sua fonte de pesquisa, ainda gera dúvidas quanto à veracidade da informação.

Tais pesquisas ficaram conhecidas como 'estúdios calchaquies', ou "questão calchaquie", pois assim se referiam os conquistadores espanhóis à população nativa que vivia naqueles vales. Naquela época, o consenso acadêmico permeava a ideia de sucessão de 'civilizações' (NASTRI, 2004), e, em 1906, como consequência desta perspectiva teórica, foram produzidas sínteses gerais, como "Alfarerias del Noroeste Argentino", do Museu de 
LaPlata, e "cronologia de las culturas extinguidas y su reciprocas vinculaciones", do Museu Etnografico da Universidade de Buenos Aires, sendo este focado em uma sistematização da cronologia arqueológica (NASTRI, 2010). Vale lembrar também que várias "tradições" arqueológicas foram estabelecidas nestas épocas, como, por exemplo, o debate sobre uma civilização diaguita de influência incaica (BOMAN, 1923; NASTRI, 2010; NASTRI e FERREIRA, 2010).

Alguns trabalhos sobre os quilmes, já no seu contexto de redução indígena no século XVII, foram desenvolvidos por Guillermina Sors em "Quilmes Colonial", em 1937. Tal trabalho se centra sobre a formação da cidade de Quilmes (parte da Grande Buenos Aires) e nos indica algumas informações sobre a dinâmica cultural dos quilmes em situação colonial baixo a tutela do Estado. Em especial, é possível acompanhar uma discussão acerca da sucessão do cacicado disputado por uma mulher, Isabel Pallamay, hoje elevada a símbolo histórico, como indica uma estátua em sua homenagem na cidade de Quilmes.

\section{Reflexividade do discurso histórico}

Algumas considerações sobre esta fase pioneira das pesquisas científicas devem ser feitas. Alguns autores, como Oscar Moro-Abadia (2006), consideram que a história da arqueologia feita até 1980 se expressa como uma forma de discurso colonial, caso consideremos o seu modus operandi internalista que define a história como ciência em termos de evolução linear de ideias. Sob esta ótica, o "contexto" (econômico, político ou relacionado a instituições religiosas), não é especialmente importante para explicar a evolução da ciência. Em contraposição a esse modelo, as abordagens "externalistas" tomam forma, justamente por elaborar uma história crítica da arqueologia, capaz de englobar o caráter social, político e econômico envolvidos na prática da arqueologia, sendo possível explorar a própria subjetividade da disciplina. Todo esse jogo de apropriações discursivas relaciona-se diretamente com a ideia de cultura material, ao impor uma abordagem que abrange não só a historicização do espaço próprio cientifico e alheio, mas também a materialidade dos objetos, como uma forma de entender os diversos processos pelos quais as noções de subjetividade são construídas a partir de uma perspectiva tanto científica quanto indígena para, em seguida, retornar à arena política com uma reivindicação própria. (LAYTON, 1994a, 1994b; JENKINS, 2001; LATOUR, 1994; STENGERS, 2002; POUGET, 2010).

Assim, os estudos pós-colônias oferecem uma ampla variedade de posições teóricas, ideias e categorias que nos ajudam a pensar os impactos das forças colonialistas e seus efeitos no que se referem à prática arqueológica. Dessa maneira, citando Gustavo Politis, Moro Abadia exemplifica o nosso contexto argentino:

In Argentina, for example, between 1879 and 1881, the national government sent several military expeditions to the enormous Pampas and Patagonia territories, as part of the so-called 'Conquest of the Desert', to areas that were inhabited by Mapuche and Tehuelche indigenous people. Some scientists accompanied these expeditions and collected archaeological and ethnographic material, as well as the heads of dead indigenous people, 
2 Atualmente, o Museu de La Plata sofre constantes reivindicações algumas contempladas por parte de certas etnias indígenas para a devolução dos restos humanos vinculados aos seus ancestrais. for bio- anthropological studies. Following military conquests, the British developed a rail network across these territories, centered around Buenos Aires, and the La Plata Museum (one of the largest museums in South America) was constructed to store and exhibit the recent achievements of the government and the scientists (POLITIS, 1995: 199). ${ }^{2}$

Entre os quilmes podemos ver os efeitos dessa arqueologia colonialista, principalmente na formação de coleções arqueológicas feitas por arqueólogos amadores e que chegam a ser institucionalizadas por autoridades municipais e provinciais, como é o caso do Museo de Arqueologia e História Cachaqui, na cidade de Cafayate, localizada próxima a "Ciudad Sagrada Quilmes" (província de Salta), aspecto este que também pode ser verificado na reconstrução de parte do sitio feito sob os auspícios de uma política mais turística do que científica (SOSA, 2007). Ultrapassando o marco de 1980, colocado por MoroAbadia, é visível, até hoje, as consequências dos processos de concessão comercial de exploração turística do sítio para terceiros, decorrente de uma política de privatização dos bens públicos que influenciou a América Latina dos anos 90 (e especialmente a Argentina). Atualmente, ainda podemos verificar atitudes colonialistas quando constatamos que o site oficial do governo da província de Tucuman insiste em denominar o sitio arqueológico como Ruina de Los Quilmes - e não Ciudad Sagrada - como atrativo turístico da região, mascarando a existência dos quilmes no local. (http://www.tucumanturismo. gov.ar. Acessado em: 26/07/2011.

\section{Grupos de interesse}

Detalhando um pouco estes processos desde uma perspectiva governamental, em 1977, durante a ditadura militar Argentina, foi realizado um plano de manejo turístico que recebeu a colaboração de alguns acadêmicos da Universidade de Buenos Aires para a reconstrução das "Ruínas del Quilmes", como atrativo turístico da província de Tucuman, realizado sob o aspecto nacionalista do "Processo de Reoganizacion Nacional" (SOSA, 2007), que valorizava grandes momentos da história colonial, mas que também tinha o intuito de fornecer elementos turísticos para a Copa do Mundo de 1978. Os critérios de manejo patrimoniais ocorreram à revelia de padrões internacionais, sendo que a arcaica estrutura turística (um museu pequeno e um café) foi logo abandonada.

Aintervenção direta do Estado nacional sobre o sitio arqueológico ocorreu entre os anos de 1977 e 1980, com a participação do Instituto de Tilcara, da Universidade de Buenos Aires, na época sob a direção de Noberto Pelissero (PELISSERO e DIFRIERI, 1981). A partir de tal intervenção, temos, portanto, um interessante paradoxo: a valorização de um monumento arqueológico - fruto de um extermínio etnocida - construído como símbolo de uma grandeza nacionalista ${ }^{3}$. Tal aspecto já era posto em marcha anteriormente e possuía consequência na própria formação territorial do país, como aponta o artigo de Carrizo (2010) "Exploraciones arqueológicas en la construcción del territorio tucumano de fines del siglo XIX y principios del siglo XX" .

Processos de construções de memórias nacionais semelhantes a esse podem ser encontrados em outros momentos da historia da formação dos Estados nacionais de outros países, como o uso de monumentos romanos e 
suas narrativas históricas, tendo como objetivo a afirmação de um determinado contexto do presente (SILVA, 2005; OLIVIER, 2005).

No caso específico da reconstrução das Ruinas Quilmes, apesar do destaque dado ao grupo quilmes (ainda que invizibilizados no contexto contemporâneo), tanto a comunidade local quanto os pesquisadores acusam o processo gerenciado pelo Estado ditatorial argentino por ter sido acompanhado por péssimas pesquisas científicas e por saques e roubos de peças arqueológicas (CURTONI e ENDERE, 2003).

Un caso distinto es el que ocurre en el Antiguo Quilmes". Todo empezó con la práctica de la "no-arqueología" de la década del 70", cuando se encaró la "restauración" del sector central del poblado sin ningún tipo de investigación arqueológica. Parece que los autores del proyecto consideraron suficiente la reconstrucción basada en las fuentes históricas (ni abundantes ni precisas), desdeñando el estudio de las evidencias materiales. No se conocen planos ni plantas de procedencia de los múltiples hallazgos que se realizaron durante el enorme proceso de remoción de que fue objeto el poblado y del que fuimos testigos impotentes. No ha quedado de dicho trabajo ni un sólo fechado de radiocarbono ni una asociación contextual de áreas de actividad con construcciones edilicias, y las escasas piezas arqueológicas que subsisten en el museo de sitio, no poseen documentación de los hallazgos (TARRAGÓ, 1999: 235 apud Marchegani et al., 2003: 55).

Com base em tais acusações, é gerada uma série de questionamentos: que grupo quilmes era interessante para o Estado ditatorial argentino? Quais foram as memórias silenciadas ou destacadas neste processo narrativo? Como a História e a Arqueologia, de acordo com seus contextos específicos, construíram as "Ruinas Quilmes"?

Depois de duas décadas, e já instaurada a democracia, foi realizada uma licitação para o manejo do sitio, ocorrendo, na prática, a sua 'privatização', à revelia de interesses locais ou de opiniões dos próprios quilmes. Assim, o empresário e artesão Hector Cruz, "vencendo" a licitação, tornou-se encarregado de expandir as obras de infraestrutura, com a instalação de um grande local de venda de artesanatos (decorrentes da exploração da mãode-obra local) e com a construção de um grande hotel, com direito a piscina e restaurante que, imediatamente, passou a ser considerado um dos pontos turísticos mais visitados da província. O descaso das autoridades públicas vis-á-vis à importância do sítio é marcante, já que tal empreendimento foi construído sobre a antiga praça comunal, sem nenhum estudo - até hoje - a respeito dos impactos arqueológicos produzidos.

A partir da exploração comercial sobre a sua herança cultural, a Comunidad Indía Quilmes (CIQ) organizou-se politicamente durante as últimas décadas, tendo como bandeira a sua visibilidade étnica - contrariando a perspectiva de desaparecimento, provocada principalmente pelo mito das "Ruinas de Quilmes" e o reconhecimento territorial. Mais recentemente, entre os anos de 2007 e 2008, os quilmes decidiram expulsar a iniciativa privada da gestão do seu patrimônio cultural. Deste modo, a CIQ tomou para si a responsabilidade de gestão do sitio arqueológico, renomeando-o, de forma paradigmática, de "Ciudad Sagrada de Quilmes". Os conflitos políticos, contudo, permaneceram, principalmente, em 
relação à Secretaria de Turismo da província de Tucuman, que não aceitou um acordo com a comunidade.

Os conflitos em questão evidenciam, mais uma vez, as disputas em torno do sentido de patrimônio mobilizadas tanto pela comunidade (BIDASECA e RUGGERO, 2011) quantos pelos agentes governamentais. Tal contexto maior, no que se refere às pesquisas arqueológicas na Argentina, pode ser conferido na obra de Maria Luz Endere (2007), "Management of Archaeological Sites and the Public in Argentina".

Situações semelhantes a esta - vale lembrar - aconteceram em diversos lugares do mundo. Nesse sentido, contribuições teóricas importantes a respeito da prática arqueológica e das alteridades indígenas foram feitas por autores como Siân Jones (1997), Robert Layton (1994a, 1994b), Bond e Gilliam (1994), Watkins (2000), Torrence e Clark (2000), Smith e Wobst (2005), Funari et al. (2005), mostrando que o interesse pelo passado e que o acesso a este é mais amplo do que os círculos acadêmicos.

Não devemos desconsiderar trabalhos como os de Nastri (2003; 2004); Tarragó (2003) ou Podgorny (1995; 2009), no âmbito da análise da história arqueológica argentina, mas torna-se relevante ressaltar, neste momento, um aspecto essencial para a compreensão da história recente dos quilmes frente ao seu patrimônio: evidenciar a questão política do controle dos processos de patrimônio, do destino e do controle dos artefatos encontrados, relacionando tais aspectos a questões de etnicidade, territorialidade, fluxo comercial e turístico, além da questão sociológica clássica do "conhecimento para quem?" (UCKO, 1995; McGUIRE, 2004; POUGET, 2010).

\section{Análise e contexto contemporâneo}

São as implicações de uma história de 'longa duração', segundo a perspectiva foucaultiana (FOUCAULT, 1969; 1979), que permitem a análise de rupturas e descontinuidades, que, por sua vez, revela subjetividades e relações de poder de um determinado caso (MARTINS, 2002). Inseridos nessa perspectiva teórica, ao se voltar o foco sobre o caso quilmes, no noroeste argentino, é possível colocar em contraste não só o registro escrito pretérito (feito pelos cronistas coloniais e as suas subjetividades), mas também o registro escrito contemporâneo (feito por arqueólogos, antropólogos, historiadores e, até mesmo, pela própria comunidade indígena, também com suas próprias subjetividades). Tal perspectiva é encontrada na análise de Fredrik Barth (1969) sobre etnicidade, especialmente, no trato sobre memoria coletiva que transmite e interpreta de modo seletivo determinados fatos históricos e personagens transformando-os em símbolos de identidade étnica e como apontam Poutignat e Streiff-Fernant (1998:13): "o que diferencia, em última instância, a identidade étnica de outras formas de identidade coletiva é o fato de ela ser orientada para o passado".

As memórias históricas (CANDAU, 2008; SANTOS, 2003), articuladas em torno deste patrimônio arqueológico de quilmes, produzem sentidos de etnicidade na comunidade e produzem reinterpretações históricas sobre o seu passado. Os contextos atuais de reivindicações de direitos civis e de reconhecimento territorial tornam expressivas estas articulações culturais para além do seio da comunidade indígena. Neste sentido, é válido compartilhar 
a reflexão de Geral Sider sobre etnohistória: "fazemos etnohistoria não através da história de uma etnia, mas pelos sentidos de historia trazido pelas etnias que estudamos." (SIDER, 1994). Assim, hoje em dia, encontram-se na Ciudad Sagrada Quilmes, não só vestígios arqueológicos dessa antiga cultura andina, mas também vestígios arqueológicos contemporâneos que refletem aspectos de dominação e de resistência - em termos marxistas, de um poder capitalista - vivenciados por esse povo. Tais aspectos configuram alguns momentos da história política e econômica capitalista transcorrida na Argentina nas últimas décadas.

O caso quilmes coloca em contraste definições clássicas de arqueologia histórica fundamentada em dicotomias, como moderno capitalista/antiguidade não-capitalista, letrado/iletrado, mito/história, primitivo/civilizado, que refletem elementos discursivos interligados (FUNARI, 2007:28). Por meio da rede discursiva - decorrente da agência humana - é possível perceber os diversos elementos históricos e os processos sociais envolvidos na constituição da Ciudad Sagrada Quilmes, tanto em termos contemporâneos quanto em termos de uma antiguidade histórica colonial. Afinal, o caco cerâmico ou aquela pedra lascada não se referem apenas a processos de representação arqueológica passados, mas também são formados pela representação trazida tanto pelo arqueólogo contemporâneo - marcado pelo seu viés político do presente (HOLTORF, 2006; 2002) - quantos pelos guias turísticos indígenas da Ciudad Sagrada, com uma interpretação muito própria sobre seu passado. 0 que se demonstra muito elucidativo quando refletimos sobre as memórias dolorosas vinculadas pelos quilmes, especialmente pelos guias turísticos da comunidade que fazem a mediação com público. Tais aspectos de memórias são os principais marcadores dessa memoria coletiva, como o cerco espanhol, o êxodo forçado, a violência dos terratenientes e o saqueio cultural. Tais elementos são essenciais na configuração de uma etnicidade, de uma noção de sujeito frente a memórias subjetivas de história. Como bem aponta Karina Bidaseca, no contexto mais amplo argentino:

Até pouco tempo atrás, os indígenas se escondiam nas cidades. Hoje começam a mostrar com orgulho crescente a sua condição (ser índio). (...) Suas identidades diaspóricas devem ser construir em torno de fronteiras culturais, de se fazer habitável a sua própria posição de fronteira (BIDASECA, 2010:152).

Um exemplo desta releitura pode ser encontrado no próprio folheto explicativo distribuído pela Comunidad Índia Quilmes aos turistas que visitam

5 As Ruínas de Quilmes ou como a comunidade prefere ser chamada "Ciudad Sagrada de Quilmes" é o marco reivindicatório territorial que engloba toda uma série de pequenas comunidades, campos de cultivo, territórios de pastagens e etc... a qual se vincula a Comunidad India Quilmes (CIQ). o imenso sitio arqueológico em seu território ${ }^{5}$, chamo especial atenção para este folheto não apenas pelos seus elementos discursivos, mas também como exemplo de organização politica que os quilmes exercem sobre o seu patrimônio:

Prolongamos la lucha heredada de nuestros antepassados y defendemos nuestro Território de todos os expropiadores, usurpadores y de las explotaciones mineras que com su contaminacion ambiental amenazan nuestra supervivencia. (...). En la ciudad de Quilmes, se desarrollo nuestra cultura, plasmaron en el arte, la medicina, la agricultura, la astrologia, la arquitectura $y$, sobre todo, en su propia espiritualidad o forma de ver el mundo. 
Muchos de estos hombres y mujeres vivieron - y murieron - en nuestra Ciudad Sagrada. Por eso, ella es un símbolo de la resistencia que el pueblo Diaguita opuso a la invasión extranjera, en la época de la conquista: en este lugar, está la sangre que derramaron nuestros mayores para defender nuestros territorios y nuestra cultura. (PANFLETO EXPLICATIVO DESTRIBUIDO PELA COMUNIDADE INDIGENA AOS TURISTAS- 2011).

Essa passagem demonstra, portanto, uma atualização da sua perspectiva histórica, uma agencialidade (Agency) em torno do sítio arqueológico e do contexto político em que se encontram. Tal contexto pode ser lido de forma mais ampla quando se refere aos impactos ambientais causados pelas atividades de mineração - atual bandeira de mobilização das comunidades indígenas da Argentina. Importante lembrar, portanto, que a dinâmica de interpretação do sitio arqueológico não se encerra nas pesquisas acadêmicas, sendo atualizada aos olhos daqueles que vivem o seu cotidiano e funcionando como elemento marcador de sua etnicidade.

\section{Conclusão}

Atualmente, uma série de artigos e de comunicações em congressos tem sido produzida em torno da situação contemporânea dos quilmes, o que nos fornece um acompanhamento de seu desenvolvimento étnico político ao longo das últimas duas décadas. Trata-se de artigos que possuem, entre si, não apenas o grupo étnico em comum, mas que refletem sobre os aspectos pós-colonialistas e os marcadores de etnicidade. Dentre eles, podemos citar os artigos de Marina Marchegiani, (et al.) (2003) Pasado, futuro y presente: la construcción de la Identidad Cultural en la Comunidad India Quilmes; (2006) Nunca serán ruinas: visiones y prácticas en torno al antiguo poblado de Quilmes en Yocavil. José Sosa (2007), "Ruinas" de Quilmes. História de un despropósito. Bidaseca, K. Ruggero, S. (2011), Quilmes, o el ominoso retorno a la re-presentación hacia Occidente. Violeta Ramirez (Comunicação RAM-2009), Políticas multiculturales en la Provincia de Tucumán?La Comunidad India de Quilmes y el Ente Tucumán Turismo en las discusiones en torno al manejo de la Ciudad Sagrada Quilmes como atractivo turístico. Laura Butafuoco, Mariela J. Hernández y Natalia A.Valdez (Comunicação RAM 2009). Diferentes procesos de patrimonialización: el caso de la Quebrada de Humahuaca y el caso de la Ciudad Sagrada de Quilmes. María Florencia Becerra et al. (Comunicação RAM 2009)¿Participación o imposición? Dinámicas de poder y saber en la reconstrucción de la "Ciudad Sagrada de Quilmes".

A reflexão da abordagem histórica e das perspectivas patrimoniais abrange, portanto, desde os primeiros momentos de percepção ontológica de grupos de interesse diversos (stakeholders) em torno do sítio arqueológico - agentes governamentais, acadêmicos e a comunidade local - até o mapeamento na qual se articulam os sentidos de etnicidade, desenvolvidos pela comunidade. $\mathrm{O}$ caso quilmes, em especial, nos oferece uma profunda reflexão sobre cultura e "cultura" (CUNHA, 2009) e a dinâmica histórica contemporânea, constatando-se que o reflexo de uma cultura trazida pela interpretação subjetiva da cultura material (seja ela mítica ou cientifica) embute uma percepção de história nessa própria cultura. 
Portanto, as dinâmicas próprias de memória e de acontecimento social que influenciam sobre essa cultura são refletidas na discursividade local acerca do seu momento histórico, da sua seleção de memória coletiva, traduzida na dinâmica patrimonial em torno do sitio arqueológico (ROTMAN, 2004). Tal é o quadro de memória étnica da Comunidad India Quilmes. Sendo assim, o exercício de se pensar a disputa patrimonial está em atualizar a reflexão acadêmica sobre os grandes momentos históricos que compõem a historiografia identitária quilmes. Isso significa superar as grandes dicotomias que compõem o quadro historiográfico no trato da questão indígena, tais como civilização/barbárie e herói/vitima (PASSETI, 2005), além de acompanhar, tanto nos textos históricos, como na abordagem da história recente, os quilmes como agentes da sua própria história.

À primeira vista, poder-se-ia pensar: "o que o sítio arqueológico quilmes tem a ver com tudo isso?". Antes de qualquer coisa, é importante lembrar que a ideia de monumento aqui tratado não se refere apenas ao âmbito de sua materialidade por si só, mas também ao de sua monumentalidade discursiva. A "Ciudad Sagrada Quilmes" é o nódulo pelo qual se dispersam diversas linhas discursivas acerca do passado, do presente e do futuro - nesse sentido, vale lembrar a noção Latouriana de rede, entendida aqui como metáfora (LATOUR, 2005).

O que também implica uma multiplicidade de questões referentes à discusividade elencada pelos quilmes (e outros grupos de interesse). De como se enxergam no mundo e de como se projetam ao mundo. O que, obviamente, decorre de uma relação muito própria com a história, com o patrimônio e com a etnicidade.

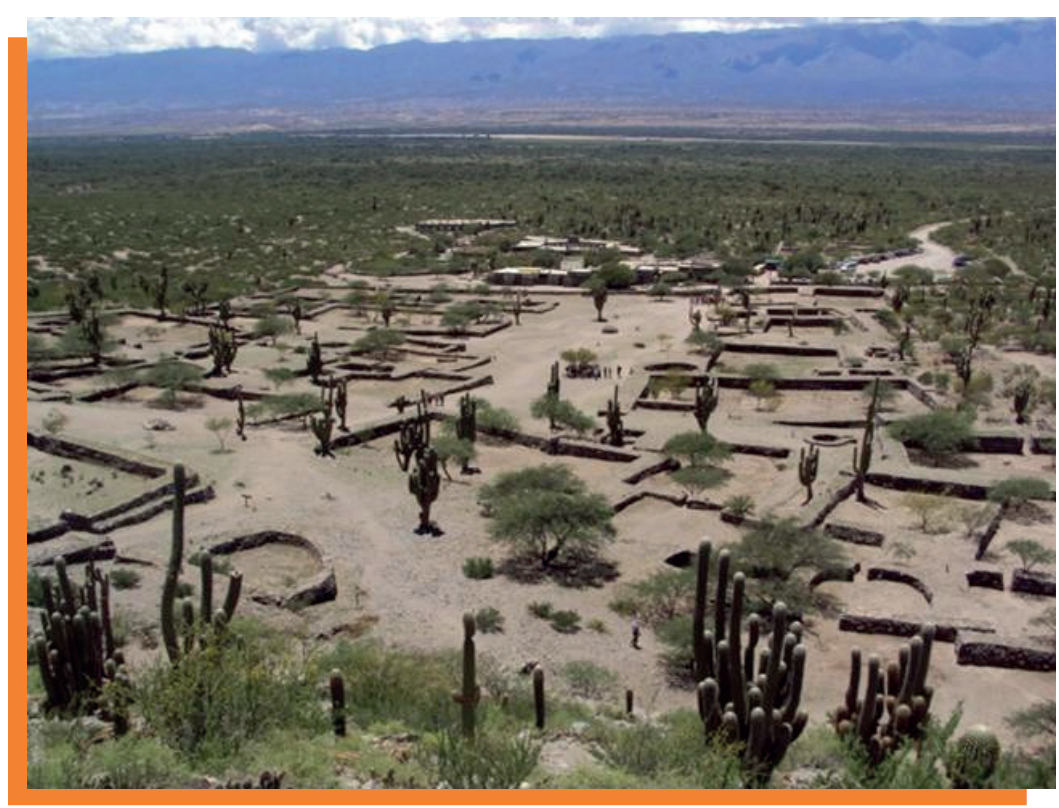

Figura 2: Vista Geral do Pátio Central 


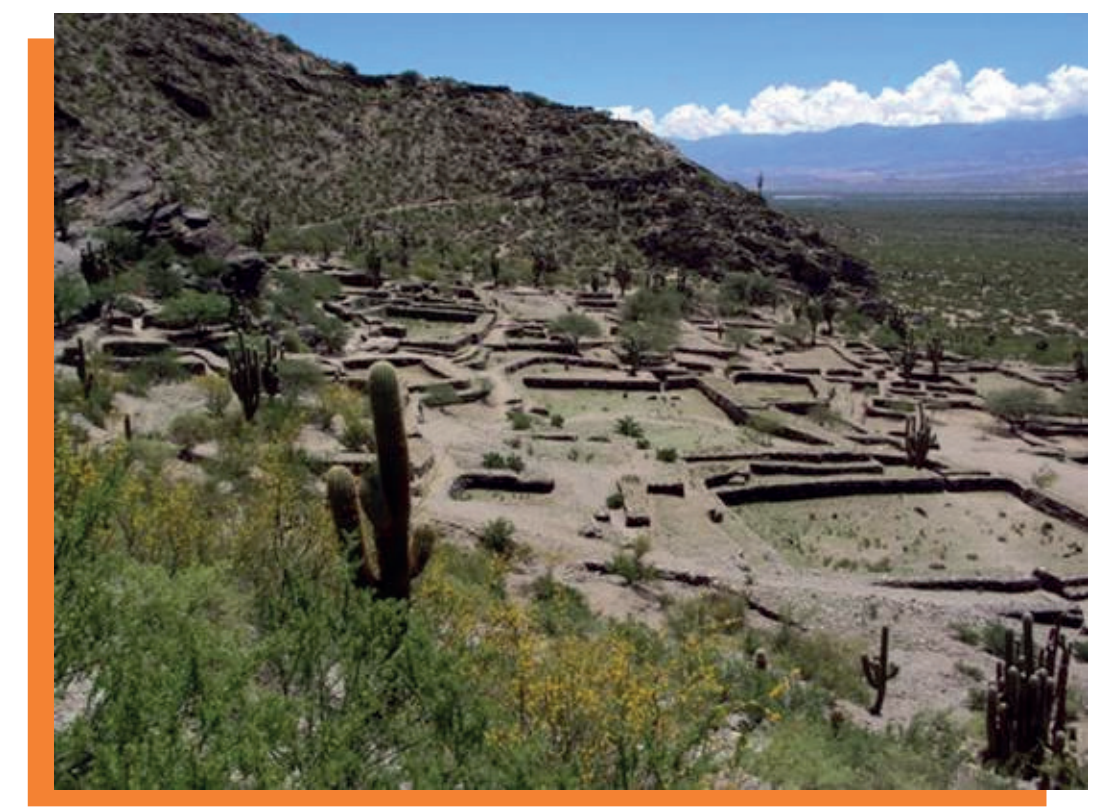

Figura 3: Vista geral

\section{Referências bibliográficas}

AMBROSETTI, J. La Antigua ciudad de Quilmes (valle Calchaqui). Boletín Instituto Geografía Argentino 17, p.33-70. 1897.

BARTH, Fredrik. Grupos Étnicos e suas fronteiras. In: POUTIGNAT, P. Teorias da etnicidade. Seguido de grupos étnicos e suas fronteiras de Fredrik Barth, Philippe Poutignat, Jocelyne Streiff-Fenard. Tradução de Elcio Fernandes. São Paulo: UNESP, p.187-227, 1998.

Ethnic groups and boundaries. The social organization of culture difference. Bergen, Oslo: Universittetsforlaget. 1969.

BIDASECA, Karina. Perturbando el texto colonial. Los Estudios (Pos) coloniales en América Latina y sus mujeres. SB: Buenos Aires. 2010.

BIDASECA, K.; RUGGERO, S. Quilmes, o el ominoso retorno a la representaciones hacia occidente. In: BIDASECA, K. (org.) Signos de la Identidad Indígena. SB: Buenos Aires. p. 33-45, 2011.

BOMAN, E. Los ensayos de establecer una cronología prehispánica en la Región Diaguita (Republica Argentina). Quito: Boletín de la Academia Nacional de Historia, 6:1-31. 1923.

BOND, G. C.; GILLIAM, A. (eds.) Social Construction of the Past. London: Routledge. 1994. CANDAU, Joel. Memoria e Identidad. Buenos Aires: Ediciones Del Sol. 2008.

CUNHA, Manuela Carneiro da. Cultura com aspas e outros ensaios. São Paulo: Cosac Naify, 2009.

CARRASCO, Morita. Los derechos de los pueblos indígenas en Argentina. International Work Group for Indigenous Affairs, Asociación de Comunidades Aborígenes (Argentina). Buenos Aires, 2000. 
CURTONI, R.; ENDERE, M. L.. "Patrimonio, arqueología y participación: Acerca de la noción de paisaje". In: Análisis, interpretación y Gestión en la Arqueología de Sudamérica. Serie Teórica n² 2. Olavarría: Incuapa, p.277-296, 2003.

CARRIZO, Sergio Rodolfo. Exploraciones arqueológicas en la construcción del territorio tucumano de fines del siglo XIX y principios del siglo XX. In: NASTRI, Javier.; FERREIRA, Lucio Menezes. (orgs.) Historias de Arqueología Sudamericana. Buenos Aires: Fundación de Historia Natural Felix de Azara, p.55-76, 2010.

ENDERE, Maria Luz. Management of Archaeological Sites and the Public in Argentina. In: BAR international Series. Oxford: Archaeopress, 2007.

FERREIRA, L. M. Internacionalismo y arqueologia: las relaciones institucionales y cientificas entre Hermann von Ihering y los museus argentinos. In: NASTRI, Javier.; FERREIRA, Lucio Menezes. (orgs.) Historias de Arqueología Sudamericana. Buenos Aires: Fundacion de Historia Natural Felix de Azara, p.77-94, 2010.

FOUCAULT. M. Microfísica do poder. Rio de Janeiro: Graal, 1979.

A arqueologia do saber. Rio de Janeiro: Forense Universitária, 1969.

FUNARI, P. P. A. et al. (eds.) Global archaeological theory: contextual voices and contemporary thoughts. Nova York: Kluwer Academic/Plenum, 2005.

Arqueologia e Patrimônio. Erechim: Habilis, 2007.

HOLTORF, C. Studying Archaeological Fieldwork in the Field. In: EDGEWORTH, M. (ed.) Ethnografies of Archaeological Practice. Lanham: Altamira Press, p.81-94, 2006.

Notes on the life history of a pot sherd. In: Journal of Material Culture, 7(1), p.49-71. 2002.

JENKINS, Keith. A história repensada. São Paulo: Contexto, 2001.

JONES, S. The Archaeology of Ethnicity. Constructing Identities in the Past and Present. London : Routledge, 1997.

LAFONE QUEVEDO, S. A. Londres y Catamarca. Cartas à La nación: 1883-84 y 85. Buenos Aires: Imprenta y Librería de Mayo, 1888.

LATOUR, Bruno. Jamais fomos modernos: ensaio de antropologia simétrica. Rio de Janeiro: Ed. 34, 1994.

Reensamblar lo social. Una indroducción a la teoria del actor-red. Buenos Aires: Manantial, 2005.

LA VAUX, H de. Execursión dans les Vallées Calchaquies (Provience de Tucuman). Poteries indigenes. In : Journal de la Societe des Americanistes de Paris. Tomo III, n.2, p.167-176. 1901.

LAYTON, R. Who needs the past? Indigenous values and archaeology. London: Routledge, 1994a.

(ed.) Conflict in the Archaeology of Living Tradition. London: Routledge, 1994b.

LORANDI, Ana Maria; BOIXADOS, Roxana. Etnohistoria de los valles calchaquies em los siglos XVI y XVII. In: Runa XVIII. Buenos Aires, p.263-419. 1988. 
LOZANO, Pedro. Historia de la conquista del Paraguay, Río de la Plata y Tucumán. Bs. As, Biblioteca del Río de la Plata. (Colección de obras, documentos y noticias inéditas o poco conocidas para servir a la historia física, política y literaria del Río de la Plata. Dirigida por Andrés Lamas), 1873.

MARCHEGIANI, M. et al. Pasado, futuro y presente: la construcción de la Identidad Cultural en la Comunidad India Quilmes (Noroeste argentino). Ms. No Prelo. 2003.

MARCHEGIANI, M.; PALAMARCZUK, V.; PRATOLONGO, G.; y REYNOSO, A. Nunca serán ruinas: visiones y prácticas en torno al antiguo poblado de Quilmes en Yocavil. In: AUSTRAL, A.; TAMAGNINI, M. (org.). Problemáticas de la Arqueología Contemporánea. Publicación del XV Congreso Nacional de Arqueología Argentina, p. 313-323. U. N. de Río Cuarto, Río Cuarto, 2006.

MARTINS, C. J. Utopias e heterotopias na obra de Michel Foucault. In: RAGO, M.; ORLANDI, L; VEIGA-NETO, A. (orgs.) Imagens de Foucault e Deleuze, ressonâncias nietszchianas. Rio de Janeiro: DPA, p. 84-98, 2002.

MCGUIRE, R. Contested Pasts: Archaeology and Native Americans. In: MESKELL, L. PREUCEL, R.W. (eds.) A companion to Social Archaeology. Oxford: Blackwell, p.374395, 2004.

MORO-ABADÍA, O. The History of Archaeology as a 'Colonial Discourse'. In: Bulletin of the History of Archaeology. 16 (2): p.4-17, 2006.

NASTRI, Javier; FERREIRA, Lucio Menezes. (orgs.) Historias de Arqueología Sudamericana. Buenos Aires: Fundación de Historia Natural Felix de Azara, 2010.

NASTRI, Javier. Una cuestión de estilo. Cronología cultural en la arqueología andina de las primeras décadas del siglo XX. In: NASTRI, Javier; FERREIRA, Lucio Menezes. (orgs.) Historias de Arqueología Sudamericana. Buenos Aires: Fundación de Historia Natural Felix de Azara, pp.95-122, 2010.

NASTRI, Javier. Aproximaciones al espacio calchaqui. In: Anales Nueva Epoca, n.6. Instituto Iberoamericano, Universidad de Gotemburgo, p.99-125. 2003.

Los primeiros americanistas (1876-1900) y la construcción arqueológica del pasado de los valles calchaquíes (noroeste Argentino). In: HABER, A. (ed.) Hacia una Arqueologia de las Arqueologias Sudamericanas. Bogota: CESO-Uniandes: p.91114. 2004.

OLIVIER, Laurent. A Arqueologia do Terceiro Reich e a França: notas para servir ao estudo da "banalidade do mal" em Arqueologia. In: FUNARI, P.P.A.; ORSER, C.; SCHIAVETTO, Solange N. (orgs.) Identidades, Discurso e Poder: Estudos de Arqueologia Contemporânea. São Paulo: Annablume; Fapesp, p.167-195, 2005.

PASSETI, Gabriel. Indígenas e criollos: política, guerra e traição nas lutas no sul da Argentina (1852-1885). Dissertação de Mestrado, História, FFLCH-USP, São Paulo, 2005.

PELISSERO, N; DIFRIERI, H. Quilmes. Arqueología y Etnohistória de una ciudad prehispánica. San Miguel de Tucumán: Universidad de Buenos Aires, 1981.

PODGORNY, I. El sendero del tiempo y de las causas accidentales. Los espacios de la prehistoria en la Argentina, 1850-1910. Rosario: Prohistoria ediciones, 2009. 
De Razón a Facultad: funciones del Museo de La Plata en el período 1890-1920. In: Runa, 22, p.89-104 1995.

POLITIS, G. The Socio-Politics of the Development of Archaeology in Hispanic South America. In: UCKO, P. (ed.) Theory in Archaeology: a world perspective. London: Routledge, p. 197-235, 1995.

POUGET, Frederic. Práticas Arqueológicas e Alteridades Indígenas. Dissertação de Mestrado. MAE-USP. 2010. Disponível em versão digital: www.teses.usp.br.

POUTIGNAT, P.; STREIFF-FERNANT. Teorias da etnicidade. Seguido de grupos étnicos e suas fronteiras de Fredrik Barth, Philippe Poutignat, Jocelyne Streiff-Fenard. Trad. Élcio Fernandes. São Paulo: UNESP, 1998.

ROTMAN, Mónica. (ed.) Antropología de la Cultura y el Patrimonio. Diversidad y desigualdad en los procesos culturalescontemporáneos. Córdoba: Ferreyra Editor, 2004.

SMITH, C.; WOBST, H. C. Indigenous Archaeologies: Decolonizing Theory and Practice. London: Routledge, 2005.

SANTOS, Myrian Sepúlveda dos. Memória Coletiva e Teoria Social. 1. ed. São Paulo: Annablume, 2003.

SARASOLA, Carlos M. Nuestros Paisanos los Indios. Buenos Aires: Editorial del Nuevo extremo, 2010.

SIDER, Gerald. Identity as History: ethnohistory, ethnogenesis, and ethnocide in the Southeastern United States. In: Identities 1, p.109-122. 1994.

SILVA, Glaydson J. A Antiguidade Romana e a Desconstrução das Identidades Nacionais. In: FUNARI, P. P. A.; ORSER, C.E.; SCHIAVETTO, S. N. O. (orgs.) Identidades, Discursos e Poder: Estudos de Arqueologia Contemporânea. São Paulo: Annablume; FAPESP, p.91-101, 2005.

SORS, G. Quilmes Colonial. Taller de impresiones oficiales: La Plata, 1937.

SOSA, J. "Ruinas" de Quilmes. História de un despropósito. 2007. Disponível em: http:// argentina.indymedia.org/uploads/2008/01/kilmes.pdf (Acesso em: 01/12/2012).

STENGERS, Isabelle. A Invenção das ciências modernas. Coleção TRANS. Editora 34: Rio de Janeiro, 2002.

TARRAGÓ, Myrian. La arqueologia de los valles calchaquies en perpectiva historica. In: Anales Nueva Época, 6: p.13-42. 2003.

TORRENCE, R.; CLARKE, A. The archaeology of difference: negotiating cross-cultural engagements in Oceania. London: Routledge, 2000.

UCKO, P. (ed.) Theory in Archaeology: a world perspective. London: Routledge, 1995.

WATKINS, J. Indigenous Archaeology: American Indian Values and Scientific Practice. Walnut Creek: Altamira Press, 2000. 